\title{
Recommended Rice Intake Levels Based on Average Daily Dose and Urinary Excretion of Cadmium in a Cadmium-Contaminated Area of Northwestern Thailand
}

\author{
Aroon La-Up' ${ }^{1}$, Phongtape Wiwatanadate', Sakda Pruenglampoo ${ }^{2}$ and Sureeporn Uthaikhup ${ }^{3}$ \\ ${ }^{1}$ Department of Community Medicine, Faculty of Medicine, Chiang Mai University, Chiang Mai, Thailand \\ ${ }^{2}$ Research Institute for Health Sciences, Chiang Mai University, Chiang Mai, Thailand \\ ${ }^{3}$ Department of Physical Therapy, Faculty of Associated Medical Sciences, Chiang Mai University, Chiang Mai, Thailand
}

\begin{abstract}
This study was performed to investigate the dose-response relationship between average daily cadmium dose (ADCD) from rice and the occurrence of urinary cadmium (U-Cd) in individuals eating that rice. This was a retrospective cohort designed to compare populations from two areas with different levels of cadmium contamination. Five-hundred and sixty-seven participants aged 18 years or older were interviewed to estimate their rice intake, and were assessed for U-Cd. The sources of consumed rice were sampled for cadmium measurement, from which the ADCD was estimated. Binary logistic regression was used to examine the association between ADCD and U-Cd (cut-off point at $2 \mu \mathrm{g} / \mathrm{g}$ creatinine), and a correlation between them was established. The lowest estimate was $\mathrm{ADCD}=0.5 \mu \mathrm{g} / \mathrm{kg}$ bw $/$ day [odds ratio $(\mathrm{OR})=$ 1.71 ; with a $95 \%$ confidence interval (CI) 1.02-2.87]. For comparison, the relationship in the contaminated area is expressed by $\mathrm{ADCD}=0.7 \mu \mathrm{g} / \mathrm{kg}$ bw/day, $\mathrm{OR}=1.84 ;$ [ $95 \% \mathrm{CI}, 1.06-3.19]$, while no relationship was found in the non-contaminated area, meaning that the highest level at which this relationship does not exist is $\mathrm{ADCD}=0.6 \mu \mathrm{g} / \mathrm{kg}$ bw/day [95\% CI, 0.99-2.95]. Rice, as a main staple food, is the most likely source of dietary cadmium. Abstaining from or limiting rice consumption, therefore, will increase the likelihood of maintaining U-Cd within the normal range. As the recommended maximum ADCD is not to exceed $0.6 \mu \mathrm{g} / \mathrm{kg}$ bw/day, the consumption of rice grown in cadmium-contaminated areas should not be more than $246.8 \mathrm{~g} /$ day. However, the exclusion of many edible plants grown in the contaminated area from the analysis might result in an estimated ADCD that does not reflect the true level of cadmium exposure among local people.
\end{abstract}

Key words: Dose-response, Average daily cadmium dose, Urinary cadmium, Binary logistic regression

\section{INTRODUCTION}

Diet is the major source of cadmium exposure for the general non-smoking Thai population. Rice is the main dietary staple of the Thai people and, because of its ability to

Correspondence to: Phongtape Wiwatanadate, Department of Community Medicine, Faculty of Medicine, Chiang Mai University, Chiang Mai, 50200, Thailand

E-mail: pwiwatanadate@gmail.com

Abbreviations: $A D C D$, average daily cadmium dose; $U-C d$, urinary cadmium

This is an Open-Access article distributed under the terms of the Creative Commons Attribution Non-Commercial License (http:// creativecommons.org/licenses/by-nc/3.0) which permits unrestricted non-commercial use, distribution, and reproduction in any medium, provided the original work is properly cited. absorb cadmium, may be an important source of this metal. Rice is consumed in several meals daily, and therefore may allow the accumulation of cadmium in the body to the extent of impairing human health over a long period of time.

Urinary cadmium (U-Cd) is a vital biomarker of longterm exposure, reflecting the total cadmium accumulation in the human body (1). Cadmium toxicity is mostly chronic in nature, arising as a result of long-term exposure of more than one year (2). In addition, U-Cd is an important indicator of whether the body's cadmium burden is at a level that is threatening to human health. However, safe levels of U$\mathrm{Cd}$ have been determined differently in different studies, because even the $0.5 \mu \mathrm{g} \mathrm{Cd} / \mathrm{g}$ creatinine level commonly found in the non-smoking population and in people living in areas without cadmium contamination has been found to have adverse effects on health $(3,4)$. However, the WHO 
has established that U-Cd levels not exceeding $2 \mu \mathrm{g} / \mathrm{g}$ creatinine are safe for the general population $(5,6)$. Thus, the safety margin between the cadmium level found in the general population and that causing cadmium toxicity is unclear. Furthermore, the average level of cadmium intake from food that will give rise to health effects has been determined differently for different areas (7-11). The Mae Sot District, in Tak Province, located in the northwestern Thailand, has had issues with environmental cadmium for more than 10 years, according to some research reports. The local population still maintains their traditional way of life, including the consumption of locally grown rice (12). Although a study was previously attempted on the human health effects of cadmium exposure in Mae Sot (13), there remains the need to explore and determine the maximum ADCD that has U-Cd implications, to prevent adverse effects on human health. In addition, there is little evidence regarding the dose-response relationship in this geographic area, while the authors are not aware of any study that involved collection of samples of cooked rice consumed by local people. Consequently, our investigation aimed to elucidate the dose-response relationship between the average daily cadmium dose (ADCD) from individuals' consumption of cooked rice and excessive U-Cd ( $\geq 2 \mu \mathrm{g} / \mathrm{g}$ creatinine). This would enable the safe level of contaminated cooked rice consumption to be calculated, to minimize adverse effects on human health.

\section{MATERIALS AND METHODS}

This observational, retrospective, epidemiological cohort study was conducted in two areas, which were suitable for comparison because of differences in their environmental cadmium levels. In contaminated areas, soil cadmium levels may be as high as $284 \mathrm{mg} / \mathrm{kg}, 1800$ times higher than levels in non-contaminated areas (14). The subjects for this study were people aged 18 or above, who had lived in one of the two areas for more than one year. The sample size was determined using StatCalc sample size and power calculations from the Epi-info 7 software program (AcaStat Software, Poinciana, FL, USA), and the samples were identified using a proportional stratified random sampling method, to ensure coverage of the populations of all villages in the areas. Samples from each village were identified by a drawing method to obtain subjects from the two different areas that were identical or similar in terms of gender and age variables.

This study was approved by the Research Ethics Committee, Faculty of Medicine, Chiang Mai University. The purpose of this investigation and the research procedures were explained to each subject before they signed the participation consent form.

Measurement of cadmium in consumed rice. A onespoonful sample of cooled, cooked rice was collected and placed in a transparent zip sachet with a label attached to its front showing the sample details. The samples were kept at room temperature and then sent to the Science and Technology Service Center, Faculty of Science, Chiang Mai University (STSC-CMU), to determine the cadmium content using the inductively coupled plasma-mass spectrometry (ICP-MS) method, which has been certified for quality by the Thai Industrial Standards Institute (TISI).

Calculation of average daily cadmium dose (ADCD). The average cadmium exposure from rice since birth, or moving into the area, until the day of sample collection was calculated using a formula adapted from the U.S. EPA (15) as follows:

$$
\mathrm{ADCD}=\frac{\mathrm{C} \times \mathrm{IR} \times \mathrm{EF} \times \mathrm{EP}}{\mathrm{BW} \times \mathrm{D}}
$$

Where ADCD is the average daily cadmium dose from rice consumption (ADCD: $\mu \mathrm{g} / \mathrm{kg}$ body weight/day); $\mathrm{C}$ is cadmium concentration in rice $(\mu \mathrm{g} / \mathrm{kg})$; IR is rice intake $(\mathrm{g} /$ day); EF is exposure frequency (days/year); EP is exposure period (years); BW is average body weight $(\mathrm{kg})$; and $\mathrm{D}$ is duration of exposure (days). The body weight average is calculated from the weight measured on the day of data collection and from medical records kept at Mea Sot General Hospital and the sub-district health promotion hospital, both of which serve the villages (Mae-Ku, Pra-That-Pha-Dang, Mae-Tao, Mae-Ka-Sa, Mae-Kued-Luang) in the research areas. IR data were collected using a semi-food frequency questionnaire (16), while EF, EP, and D were obtained by means of questionnaire interview.

Measurements of $\boldsymbol{U}-\boldsymbol{C} \boldsymbol{d}$. Subjects' second voided morning urine samples were collected. Specimen aliquots of $3 \mathrm{~mL}$ were frozen at $-20^{\circ} \mathrm{C}$ until they could be tested in the laboratory. U-Cd concentration was analyzed using graphite furnace atomic absorption spectrometry (Varian Model AA280Z, Palo Alto, CA, USA) at the Mae Sot General Hospital laboratory, and the test results were quality-assured using Lyphocheck ${ }^{\circledR}$ (Bio-Rad, Gladesville, New South Wales, Australia).

Statistical analysis. Results from the studied samples were expressed in terms of percentage, arithmetic mean, and standard deviation. Quantitative analysis was performed by transforming the data into logarithms to obtain geometric means. Then, a chi-square test was used to compare proportions between the two sample groups. Additionally, an ANOVA or Mann-Whitney U test was used for comparisons between means.

The prevalence of $\mathrm{U}-\mathrm{Cd}$ was determined using $\geq 2 \mu \mathrm{g} / \mathrm{g}$ creatinine as the cut-off value. Statistical results from logistic regression using SPSS ver. 22 (IBM, Singapore) were used to evaluate the dose-response relationship between ADCD and $\mathrm{U}-\mathrm{Cd}$ at each location, where the prevalence of $\mathrm{U}-\mathrm{Cd}$ is a criterion variable and ADCD is an explanatory variable. 
Table 1. Demographic characteristics of study participants

\begin{tabular}{llcccc}
\hline \hline & Group & $\begin{array}{c}\text { Contaminated } \\
\mathrm{n}=288\end{array}$ & $\begin{array}{c}\text { Non-contaminated } \\
\mathrm{n}=279\end{array}$ & $\begin{array}{c}\text { Total } \\
\mathrm{n}=567\end{array}$ & $p_{\text {-value }}$ \\
\hline \multirow{2}{*}{ Sex } & Male & $145(50.3)$ & $132(47.3)$ & $277(48.9)$ & 0.470 \\
& Female & $143(49.7)$ & $147(52.7)$ & $290(51.1)$ & \\
Age & $<25$ & $57(19.8)$ & $52(18.6)$ & $109(19.2)$ & 0.991 \\
& $25 \sim 34$ & $56(19.4)$ & $52(18.6)$ & $108(19.0)$ & \\
& $35 \sim 44$ & $59(20.5)$ & $58(20.8)$ & $117(20.6)$ & $116(20.5)$ \\
& $45 \sim 54$ & $57(19.8)$ & $59(21.1)$ & $117(20.6)$ & \\
Smoking & $55+$ & $59(20.5)$ & $58(20.8)$ & $145(25.6)$ & 0.319 \\
& Current & $70(24.3)$ & $14(26.9)$ & $37(6.5)$ & \\
\hline
\end{tabular}

${ }^{a}$ Result of chi-square test.

\section{RESULTS}

From a total of 567 observations, no statistically significant difference was found in terms of gender, age, and smoking status between the two groups of individuals, who were divided into those living in the contaminated and noncontaminated areas (Table 1).

The group geometric means of U-Cd concentration were 1.32 and $0.47 \mu \mathrm{g} / \mathrm{g}$ creatinine for those from the contaminated and non-contaminated areas, respectively. A statistically significant difference existed between the two groups, indicating that those living in the contaminated area, even when subdivided on the basis of gender, age, and smoking status, had higher U-Cd concentrations than their counterparts. Considering gender, although both males and females in the contaminated area had significantly higher U-Cd concentrations, females in both areas appeared to have higher levels than their male counterparts. Age was found to be positively associated with U-Cd concentration only in the contaminated area $(p<0.05)$ (Table 2).

As shown in Table 3, the median value of average daily cadmium dose from rice is $0.06 \mu \mathrm{g} / \mathrm{kg}$ bw/day. There is no difference with respect to gender and age variables, but a difference exists between the median value in the contaminated area $(0.29 \mu \mathrm{g} / \mathrm{kg}$ bw/day $)$ and that in the non-contaminated area $(0.00 \mu \mathrm{g} / \mathrm{kg}$ bw/day $)$. The variety of rice was also a significant factor, with the median value for RD6 rice consumers $(0.28 \mu \mathrm{g} / \mathrm{kg}$ bw/day $)$ being higher than that for KDML105 consumers $(0.04 \mu \mathrm{g} / \mathrm{kg}$ bw/day $)$.

The prevalence of U-Cd $\geq 2 \mu \mathrm{g} / \mathrm{g}$ creatinine (Table 4 ) differs at a statistically significant level, with 101 people $(35.1 \%)$ in the contaminated area and 20 people $(7.2 \%)$ in the non-contaminated area having levels of this magnitude.

The investigation of the dose-response relationship between ADCD from rice and U-Cd based on the data from all studied subjects shows $\mathrm{ADCD}=0.5 \mu \mathrm{g} / \mathrm{kg}$ bw/day to be at a statistically significant level, with an odds ratio $(\mathrm{OR})=$ $1.71,95 \% \mathrm{CI}=1.02 \sim 2.87$. The OR increases when ADCD increases, after adjusting for gender, age, smoking status,
Table 2. Mean concentration of cadmium in urine $(\mu \mathrm{g} / \mathrm{g}$ creatinine) by demographic characteristics

\begin{tabular}{|c|c|c|c|c|c|}
\hline \multirow{2}{*}{ Characteristics } & \multirow{2}{*}{ Group } & \multicolumn{2}{|c|}{ Contaminated } & \multicolumn{2}{|c|}{ Non-contaminated } \\
\hline & & $\mathrm{GM}^{\mathrm{a}}$ & $\mathrm{GSD}^{\mathrm{b}}$ & $\mathrm{GM}^{\mathrm{a}}$ & $\mathrm{GSD}^{\mathrm{b}}$ \\
\hline \multirow[t]{3}{*}{ Sex } & Male & 1.10 & 3.14 & 0.36 & 2.30 \\
\hline & Female & 1.59 & 2.43 & 0.60 & 2.34 \\
\hline & $p$-value ${ }^{\mathrm{c}}$ & \multicolumn{2}{|c|}{0.003} & \multicolumn{2}{|c|}{$<0.01$} \\
\hline \multirow[t]{6}{*}{ Age } & $<25$ & $0.60^{\mathrm{d}}$ & 2.69 & 0.41 & 2.69 \\
\hline & $25 \sim 34$ & $0.98^{\mathrm{e}}$ & 2.29 & 0.55 & 3.45 \\
\hline & $35 \sim 44$ & $1.51^{\mathrm{f}}$ & 2.75 & 0.47 & 2.95 \\
\hline & $45 \sim 54$ & $1.91^{\mathrm{g}}$ & 2.57 & 0.41 & 2.57 \\
\hline & $\geq 55$ & $2.24^{\mathrm{h}}$ & 2.40 & 0.52 & 2.13 \\
\hline & $p$-value ${ }^{\mathrm{c}}$ & \multicolumn{2}{|c|}{0.006} & \multicolumn{2}{|c|}{0.235} \\
\hline \multirow[t]{4}{*}{ Smoking } & Current & 1.10 & 2.69 & 0.46 & 2.45 \\
\hline & Ex-smoker & 1.82 & 2.57 & 0.33 & 2.57 \\
\hline & Never & 1.35 & 2.88 & 0.49 & 2.40 \\
\hline & $p$-value ${ }^{\mathrm{c}}$ & \multicolumn{2}{|c|}{0.096} & \multicolumn{2}{|c|}{0.250} \\
\hline \multicolumn{2}{|l|}{$\begin{array}{l}\text { Total } \\
p \text {-value }\end{array}$} & \multicolumn{4}{|c|}{$<0.01$} \\
\hline
\end{tabular}

${ }^{\mathrm{a} G e o m e t r i c ~ m e a n . ~}$

${ }^{\mathrm{b}}$ Geometric standard deviation.

'Result of ANOVA followed by LSD test for multiple comparisons among group.

d'Significant difference VS 25-34, 35-44, 45-54, and 55 or greater at $p<0.05$.

'Significant difference VS $<25,35-44,45-54$, and 55 or greater at $p<0.05$.

fSignificant difference VS $<25,25-43$, and 55 or greater at $p<0.05$.

${ }^{9}$ Significant difference VS $<25$ and $25-34$ at $p<0.05$.

hignificant difference VS $<25,25-34$, and 35-44 at $p<0.05$.

and location. When location is taken into account, the findings reveal that this relationship exists at an ADCD of 0.7 $\mu \mathrm{g} / \mathrm{kg}$ bw/day with an $\mathrm{OR}=1.84,95 \% \mathrm{CI}=1.06 \sim 3.19$ in the contaminated area; whereas in the non-contaminated area, a statistical relationship cannot be established, due to the absence of ADCD at $\geq 0.7 \mu \mathrm{g} / \mathrm{kg}$ bw/day (Table 5).

Table 6 shows the estimated consumption of rice with varying degrees of cadmium contamination, but not exceeding $400 \mu \mathrm{g} / \mathrm{kg}$ as recommended by CODEX, categorized by 
Table 3. Rice consumption and average daily cadmium intake by demographic and rice group

\begin{tabular}{|c|c|c|c|}
\hline & Group & Rice consumption (g/day $)^{\mathrm{a}}$ & Average daily cadmium dose $(\mu \mathrm{g} / \mathrm{kg} \text { bw/day })^{\mathrm{a}}$ \\
\hline \multirow[t]{3}{*}{ Sex } & Male & $431.26 \pm 204.91$ & $0.52 \pm 1.43^{\mathrm{a}}(0.05)^{\mathrm{b}}$ \\
\hline & Female & $319.28 \pm 313.71$ & $0.36 \pm 0.79^{\mathrm{a}}(0.06)^{\mathrm{b}}$ \\
\hline & $p$-value & $<0.01^{\mathrm{c}}$ & $0.402^{f}$ \\
\hline \multirow[t]{6}{*}{ Age } & $<25$ & $345.64 \pm 173.29^{d}$ & $0.31 \pm 0.73^{\mathrm{a}}(0.06)^{\mathrm{b}}$ \\
\hline & $25 \sim 34$ & $343.75 \pm 168.66^{\mathrm{d}}$ & $0.59 \pm 1.68^{\mathrm{a}}(0.07)^{\mathrm{b}}$ \\
\hline & $35 \sim 44$ & $366.67 \pm 213.99^{d}$ & $0.26 \pm 0.67^{\mathrm{a}}(0.04)^{\mathrm{b}}$ \\
\hline & $45 \sim 54$ & $450.67 \pm 469.16^{\mathrm{e}}$ & $0.59 \pm 1.29^{\mathrm{a}}(0.08)^{\mathrm{b}}$ \\
\hline & $\geq 55$ & $359.62 \pm 185.61^{\mathrm{d}}$ & $0.44 \pm 1.06^{\mathrm{a}}(0.04)^{\mathrm{b}}$ \\
\hline & $p$-value & $0.016^{\mathrm{c}}$ & $0.080^{\mathrm{g}}$ \\
\hline \multirow[t]{2}{*}{ Location } & Contaminated & $325.42 \pm 151.17$ & $0.83 \pm 1.51^{\mathrm{a}}(0.29)^{\mathrm{b}}$ \\
\hline & $\begin{array}{l}\text { Non-contaminated } \\
p \text {-value }\end{array}$ & $\begin{array}{c}424.13 \pm 341.04 \\
<0.01^{\mathrm{c}}\end{array}$ & $\begin{array}{c}0.03 \pm 0.07^{\mathrm{a}}(0.00)^{\mathrm{b}} \\
<0.01^{\mathrm{f}}\end{array}$ \\
\hline \multirow[t]{3}{*}{ Rice } & KDML-105 & $388.63 \pm 298.43$ & $0.24 \pm 0.59^{\mathrm{a}}(0.04)^{\mathrm{b}}$ \\
\hline & RD6 & $327.15 \pm 150.45$ & $1.10 \pm 1.98^{\mathrm{a}}(0.28)^{\mathrm{b}}$ \\
\hline & $p$-value & $0.002^{\mathrm{c}}$ & $<0.01^{\mathrm{f}}$ \\
\hline Total & & $373.99 \pm 271.78$ & $0.44 \pm 1.15^{\mathrm{a}}(0.06)^{\mathrm{b}}$ \\
\hline
\end{tabular}

${ }^{\mathrm{a}}$ Arithmetric mean \pm standard deviation.

${ }^{\mathrm{b}}$ Median.

'Result of ANOVA followed by LSD test for multiple comparisons among group.

'Significant difference VS 45-54 at $p<0.05$.

eSignificant difference VS $<25,25-34,35-44$, and 55 or greater at $p<0.05$.

Result of Mann-Whitney U test.

${ }^{9}$ Result of Kruskal-Wallis test.

Table 4. Prevalence of U-Cd by location

\begin{tabular}{cccc}
\hline \hline U-Cd & $\begin{array}{c}\text { Contaminated } \\
\mathrm{n}=288\end{array}$ & $\begin{array}{c}\text { Non-contaminated } \\
\mathrm{n}=279\end{array}$ & $p$-value \\
\hline$<2 \mu \mathrm{g} / \mathrm{g}$ creatinine & $187(64.9)$ & $259(92.8)$ & $<0.01$ \\
$\geq 2 \mu \mathrm{g} / \mathrm{g}$ creatinine & $101(35.1)$ & $20(7.2)$ & \\
\hline
\end{tabular}

Result of chi-square test.

Table 5. Logistic regression analysis of the dose-response relationship between average daily cadmium dose (ADCD) and urinary cadmium (U-Cd) cut-off point at $2 \mu \mathrm{g} / \mathrm{g}$ creatinine

\begin{tabular}{|c|c|c|c|c|c|c|c|c|c|}
\hline \multirow{2}{*}{ ADCD } & \multicolumn{3}{|c|}{ Contaminated } & \multicolumn{3}{|c|}{ Non-contaminated } & \multicolumn{3}{|c|}{ Overall } \\
\hline & $\mathrm{OR}_{\mathrm{adj}}{ }^{\mathrm{a}}$ & $95 \% \mathrm{CI}$ & $p$-value & $\mathrm{OR}_{\mathrm{adj}}{ }^{\mathrm{a}}$ & $95 \% \mathrm{CI}$ & $p$-value & $\mathrm{OR}_{\mathrm{adj}}^{\mathrm{b}}$ & $95 \% \mathrm{CI}$ & $p$-value \\
\hline 0.1 & 0.86 & $0.5 \sim 1.5$ & 0.598 & 0.5 & $0.1 \sim 4.3$ & 0.052 & 0.9 & $0.5 \sim 1.5$ & 0.868 \\
\hline 0.2 & 0.96 & $0.6 \sim 1.6$ & 0.870 & 0 & 0 & 0.999 & 1.0 & $0.6 \sim 1.6$ & 0.924 \\
\hline 0.3 & 1.19 & $0.7 \sim 2.0$ & 0.511 & 0 & 0 & 0.999 & 1.2 & $0.7 \sim 2.0$ & 0.447 \\
\hline 0.4 & 1.31 & $0.8 \sim 2.2$ & 0.313 & 0 & 0 & 0.999 & 1.4 & $0.8 \sim 2.2$ & 0.249 \\
\hline 0.5 & 1.68 & $0.9 \sim 2.9$ & 0.059 & 0 & 0 & 0.999 & 1.7 & $1.1 \sim 2.9$ & 0.042 \\
\hline 0.6 & 1.71 & $1.0 \sim 2.9$ & 0.052 & 0 & 0 & 0.999 & 1.7 & $1.1 \sim 2.9$ & 0.044 \\
\hline 0.7 & 1.84 & $1.1 \sim 3.2$ & 0.032 & - & - & - & 1.8 & $1.1 \sim 3.1$ & 0.025 \\
\hline 0.8 & 1.89 & $1.1 \sim 3.3$ & 0.027 & - & - & - & 1.9 & $1.1 \sim 3.3$ & 0.020 \\
\hline 0.9 & 2.26 & $1.3 \sim 4.0$ & 0.005 & - & - & - & 2.3 & $1.3 \sim 4.0$ & 0.004 \\
\hline 1.0 & 2.22 & $1.2 \sim 4.1$ & 0.010 & - & - & - & 2.2 & $1.2 \sim 4.0$ & 0.007 \\
\hline
\end{tabular}

${ }^{\mathrm{a}}$ Odds ratio adjusted for sex, age, and smoking.

${ }^{\mathrm{b}}$ Odds ratio adjusted for sex, age, smoking, and location.

$\mathrm{OR}_{\mathrm{adj}}=$ adjusted odds ratio.

gender, for different age groups, as well as overall results for the different age groups. The estimation was made by applying the formula for calculating ADCD. Since, in this case, the highest level of ADCD found to have no relationship with U-Cd is $0.6 \mu \mathrm{g} / \mathrm{kg}$ bw/day, this figure was used for back-calculation or inference of rice intake, taking into 
Table 6. Estimated rice intake by sex, age, and cadmium concentration in rice when $A D C D=0.6 \mu \mathrm{g} / \mathrm{kg}$ bw/day

\begin{tabular}{|c|c|c|c|c|c|c|c|c|c|c|}
\hline \multirow{3}{*}{ Sex } & \multirow{3}{*}{ Age } & \multicolumn{9}{|c|}{ Estimated rice intake (g/day) } \\
\hline & & $<49$ & $50 \sim 99$ & $100 \sim 149$ & $150 \sim 199$ & $200 \sim 249$ & $250 \sim 299$ & $300 \sim 299$ & $350 \sim 399$ & $0.141^{\mathrm{a}}$ \\
\hline & & \multicolumn{9}{|c|}{ Cadmium concentration in rice $(\mu \mathrm{g} / \mathrm{kg})$} \\
\hline \multirow[t]{5}{*}{ Male } & $18 \sim 24$ & 740.8 & 366.7 & 243.6 & 182.4 & 145.8 & 121.4 & 104.0 & 91.0 & 257.4 \\
\hline & $25 \sim 34$ & 775.1 & 383.6 & 254.9 & 190.9 & 152.5 & 127.0 & 108.8 & 95.2 & 269.4 \\
\hline & $35 \sim 44$ & 786.1 & 389.1 & 258.5 & 193.6 & 154.7 & 128.8 & 110.4 & 96.5 & 273.2 \\
\hline & $45 \sim 54$ & 759.2 & 375.8 & 249.7 & 186.9 & 149.4 & 124.4 & 106.6 & 93.2 & 263.8 \\
\hline & $55+$ & 710.2 & 351.5 & 233.6 & 174.9 & 139.8 & 116.4 & 99.7 & 87.2 & 246.8 \\
\hline \multirow[t]{5}{*}{ Female } & $18 \sim 24$ & 619.6 & 306.7 & 203.8 & 152.6 & 121.9 & 101.5 & 87.0 & 76.1 & 215.3 \\
\hline & $25 \sim 34$ & 680.8 & 337.0 & 223.9 & 167.6 & 134.0 & 111.6 & 95.6 & 83.6 & 236.6 \\
\hline & $35 \sim 44$ & 645.3 & 319.4 & 212.2 & 158.9 & 127.0 & 105.8 & 90.6 & 79.2 & 224.3 \\
\hline & $45 \sim 54$ & 699.2 & 346.1 & 229.9 & 172.2 & 137.6 & 114.6 & 98.2 & 85.9 & 243.0 \\
\hline & $55+$ & 679.6 & 336.4 & 223.5 & 167.3 & 133.7 & 111.4 & 95.4 & 83.5 & 236.2 \\
\hline \multirow[t]{5}{*}{ Overall } & $18 \sim 24$ & 655.5 & 324.5 & 215.6 & 161.4 & 129.0 & 107.4 & 92.0 & 80.5 & 227.8 \\
\hline & $25 \sim 34$ & 742.3 & 367.4 & 244.1 & 182.8 & 146.1 & 121.7 & 104.2 & 91.2 & 258.0 \\
\hline & $3 \sim 44$ & 734.0 & 363.3 & 241.4 & 180.7 & 144.4 & 120.3 & 103.1 & 90.1 & 255.1 \\
\hline & $45 \sim 54$ & 747.4 & 369.9 & 245.8 & 184.0 & 147.1 & 122.5 & 104.9 & 91.8 & 259.7 \\
\hline & $55+$ & 704.2 & 348.5 & 231.6 & 173.4 & 138.6 & 115.4 & 98.9 & 86.5 & 244.7 \\
\hline Total average & & 710.2 & 351.5 & 233.6 & 174.9 & 139.8 & 116.4 & 99.7 & 87.2 & 246.8 \\
\hline
\end{tabular}

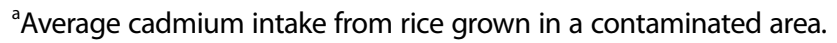

account the average body weight, for different categories of gender, age, and cadmium concentration in rice. To summarize the findings, the population in general should consume locally grown rice at a rate of no more than $246.8 \mathrm{~g} / \mathrm{kg}$ per day (in the case where cadmium concentration of the rice is not known), but they can refer to the information in Table 6 for a recommended rate of rice intake if the cadmium concentration in the rice is known. However, rice containing more than $400 \mu \mathrm{g} / \mathrm{kg}$ cadmium should not be consumed.

\section{DISCUSSION}

This study attempted to gain an insight into the relationship between ADCD from rice and U-Cd. It is imperative to prevent the adverse effects of excessive cadmium intake on human health, and U-Cd represents a good indicator of its physiological impact. Although there have been several studies addressing a dose-response relationship between dietary cadmium intake and rice consumption (17-19), the findings are quite diverse, leading to differing conclusions across the different locations and regions of the studies.

It is quite a formidable task to definitively determine the level of cadmium exposure that imposes a burden on the body. However, U-Cd is a good biomarker of exposure, as it reflects the presence of cadmium in the human body and indicates the likely extent of the damage to such target organs as the kidneys and bones (20). To prevent adverse health impacts from excessive cadmium exposure, a maximum level of cadmium exposure has been established for the general population of $2 \mu \mathrm{g} / \mathrm{g}$ creatinine $(5,6)$. In Thailand, rice is the staple food, and Thai people consume large amounts of it in several meals each day (21). It is recognized that rice is a crop that can absorb cadmium well (22). Rice thus becomes a major source of cadmium exposure among people in our studied areas. In this study, the calculation of an average daily cadmium dose (ADCD) not only used cadmium concentration in rice, but also took into account the daily rice intake and the duration of exposure. In addition, the authors of this study collected samples of cooked rice consumed by the participants to enable the cadmium content of the rice to analyzed. This is the first attempt by scholars or researchers in Thailand working on the relationship between ADCD and U-Cd to use individual people and cooked rice as the basis for assessing cadmium exposure.

The study showed a positive relationship between ADCD and the prevalence of $\mathrm{U}-\mathrm{Cd} \geq 2 \mu \mathrm{g} / \mathrm{g}$ creatinine, but only in the contaminated area. We also found that $\mathrm{ADCD}=0.6 \mu \mathrm{g} /$ $\mathrm{kg} \mathrm{bw/day}$ is the highest level at which no statistically significant relationship between ADCD and U-Cd exists. This is in contrast to a previous study undertaken in the same geographic area, with the same demographic coverage, showing that daily intake of $2.9 \sim 11.7 \mu \mathrm{g} / \mathrm{kg}$ bw/day had negative implications for public health (14). However, our results are in agreement with what was suggested at the 61st JECFA 2003 , that a level of $0.4 \sim 0.6 \mu \mathrm{g} / \mathrm{kg}$ bw/day has implications for public health (23).

In this study, recommended daily rice intake was estimated on the basis of gender, age, and cadmium concentration in rice, because rice intake was hypothesized to vary significantly across groups and sub-groups. The findings suggest that rice with lower cadmium content could be consumed in larger quantities each day and vice versa. The popu- 
lation living in the contaminated area should be referred to this information to encourage them to restrict their daily rice intake in accordance with the known level of cadmium in the rice they grow and consume. In the absence of more precise knowledge, those in the contaminated area are advised to consume no more than $264.8 \mathrm{~g} /$ day of locally grown rice. Any rice known to have a cadmium concentration greater than $400 \mu \mathrm{g} / \mathrm{kg}$ should not be consumed at all according to CODEX (23). Although rice is the main source of cadmium exposure for people in contaminated areas, they might also ingest cadmium from other edible cadmium-absorbing crops that were not surveyed in the study.

This present study faced some limitations due to ethical concerns and operational practicality. The ADCD was estimated using average body weight, obtained from measurements at the time of the investigation and from medical records only, as weight records were not available from elsewhere. School records would have been particularly useful when the study participants were aged 18 years or older. In addition, the ADCD estimated only from rice consumption might not accurately reflect the true ADCD, as information regarding rice intake in the past may be associated with recall bias.

\section{ACKNOWLEDGMENTS}

This study was supported by funds from the Faculty of Medicine, Chiang Mai University and National Research Council of Thailand (NRCT).

\section{CONFLICT OF INTEREST}

The authors declare they have no competing financial interest.

Received April 20, 2017; Revised June 7, 2017; Accepted July 4, 2017

\section{REFERENCES}

1. Vacchi-Suzzi, C., Kruse, D., Harrington, J., Levine, K. and Meliker, J.R. (2016) Is urinary cadmium a biomarker of longterm exposure in humans? A review. Curr. Environ. Health Rep., 3, 450-458.

2. Agency for Toxic Substances and Disease Registry (2008) Toxicological profile for cadmium, U.S. Department Of Health And Human Services Public Health Service, Atlanta, Georgia.

3. Ilmiawati, C., Yoshida, T., Itoh, T., Nakagi, Y., Saijo, Y., Sugioka, Y., Sakamoto, M., Ikegami, A., Ogawa, M. and Kayama, F. (2015) Biomonitoring of mercury, cadmium, and lead exposure in Japanese children: a cross-sectional study. Environ. Health Prev. Med., 20, 18-27.

4. Järup, L. and Akesson, A. (2009) Current status of cadmium as an environmental health problem. Toxicol. Appl. Pharmacol., 238, 201-208.
5. Ke, S., Cheng, X.-Y., Zhang, J.-Y., Jia, W.-J., Li, H., Luo, H.-F., Ge, P.-H., Liu, Z.-M., Wang, H.-M., He, J.-S. and Chen, Z.N. (2015) Estimation of the benchmark dose of urinary cadmium as the reference level for renal dysfunction: a large sample study in five cadmium polluted areas in China. BMC Public Health, 15, 656.

6. Weaver, V.M., Kim, N.-S., Lee, B.-K., Parsons, P.J., Spector, J., Fadrowski, J., Jaar, B.G., Steuerwald, A.J., Todd, A.C., Simon, D. and Schwartz, B.S. (2011) Differences in urine cadmium associations with kidney outcomes based on serum creatinine and cystatin C. Environ. Res., 111, 1236-1242.

7. Egan, S.K., Bolger, P.M. and Carrington, C.D. (2007) Update of US FDA's Total Diet Study food list and diets. J. Expo. Sci. Environ. Epidemiol., 17, 573-582.

8. Kido, T., Sunaga, K., Nishijo, M., Nakagawa, H., Kobayashi, E. and Nogawa, K. (2004) The relation of individual cadmium concentration in urine with total cadmium intake in Kakehashi River basin, Japan. Toxicol. Lett., 152, 57-61.

9. Kobayashi, E., Okubo, Y., Suwazono, Y., Kido, T. and Nogawa, K. (2002) Dose-response relationship between total cadmium intake calculated from the cadmium concentration in rice collected from each household of farmers and renal dysfunction in inhabitants of the Jinzu River basin, Japan. $J$. Appl. Toxicol., 22, 431-436.

10. Llobet, J., Falco, G., Casas, C., Teixido, A. and Domingo, J. (2003) Concentrations of arsenic, cadmium, mercury, and lead in common foods and estimated daily intake by children, adolescents, adults, and seniors of Catalonia, Spain. J. Agric. Food Chem., 51, 838-842.

11. Munoz, O., Bastias, J.M., Araya, M., Morales, A., Orellana, C., Rebolledo, R. and Velez, D. (2005) Estimation of the dietary intake of cadmium, lead, mercury, and arsenic by the population of Santiago (Chile) using a Total Diet Study. Food Chem. Toxicol., 43, 1647-1655.

12. Chunhabundit, R. (2016) cadmium exposure and potential health risk from foods in contaminated area, Thailand. Toxicol. Res., 32, 65-72.

13. Swaddiwudhipong, W., Nguntra, P., Kaewnate, Y., Mahasakpan, P., Limpatanachote, P., Aunjai, T., Jeekeeree, W., Punta, B., Funkhiew, T. and Phopueng, I. (2015) Human health effects from cadmium exposure: comparison between persons living in cadmium-contaminated and non-contaminated areas in Northwestern Thailand. Southeast Asian J. Trop. Med. Public Health, 46, 133-142.

14. Simmons, R.W., Pongsakul, P., Saiyasitpanich, D. and Klinphoklap, S. (2005) Elevated levels of cadmium and zinc in paddy soils and elevated levels of cadmium in rice grain downstream of a zinc mineralized area in Thailand: implications for public health. Environ. Geochem. Health, 27, 501511.

15. U.S. Environmental Protection Agency (1992) Guidelines for Exposure Assessment.

16. Guest, C. (1992) Design concepts in nutritional epidemiology. J. Epidemiol. Community Health, 46, 317.

17. Kido, T. and Nogawa, K. (1993) Dose-response relationship between total cadmium intake and $\beta_{2}$-microglobulinuria using logistic regression analysis. Toxicol. Lett., 69, 113-120.

18. Kobayashi, E., Okubo, Y., Suwazono, Y., Kido, T., Nishijo, M., Nakagawa, H. and Nogawa, K. (2002) Association between 
total cadmium intake calculated from the cadmium concentration in household rice and mortality among inhabitants of the cadmium-polluted Jinzu River basin of Japan. Toxicol. Lett., 129, 85-91.

19. Ogawa, T., Kobayashi, E., Okubo, Y., Suwazono, Y., Kido, T. and Nogawa, K. (2004) Relationship among prevalence of patients with Itai-itai disease, prevalence of abnormal urinary findings, and cadmium concentrations in rice of individual hamlets in the Jinzu River basin, Toyama prefecture of Japan. Int. J. Environ. Health Res., 14, 243-252.

20. Satarug, S. and Moore, M.R. (2004) Adverse health effects of chronic exposure to low-level cadmium in foodstuffs and cigarette smoke. Environ. Health Perspect., 112, 1099-1103.

21. Titapiwatanakun, B. (2012) The Rice Situation In Thailand, Technical Assistance Consultant's Report, TA-REG, 74595.

22. Uraguchi, S. and Fujiwara, T. (2012) Cadmium transport and tolerance in rice: perspectives for reducing grain cadmium accumulation. Rice (NY), 5, 5.

23. Codex Alimentarius Commission (2011) Report of the 35th session of the Codex Committee on Food Additives and Contaminants, Fifth session, The Hague, The Netherlands. 